\title{
Retraction notice for: "IncRNA CCAT1 promotes cell proliferation, migration, and invasion by down- regulation of miR-143 in FTC-133 thyroid carcinoma cell line" [Braz J Med Biol Res (2018) 51(6): e7046]
}

\author{
Tianzheng Yang ${ }^{1}$, Hongyan Zhai ${ }^{1}$, Ruihong Yan ${ }^{1}$, Zhenhu Zhou ${ }^{1}$, Lei Gao ${ }^{1}$, and Luqing Wang ${ }^{2}$ \\ ${ }^{1}$ Department of Nuclear Medicine, Liaocheng People's Hospital, Liaocheng, Shandong, China \\ ${ }^{2}$ Department of Radioimmunoassay, Liaocheng People's Hospital, Liaocheng, Shandong, China
}

Retraction for: Braz J Med Biol Res | doi: 10.1590/1414-431x20187046 | PMID: 29791590 | PMCID: PMC6002139

The authors would like to retract the article "IncRNA CCAT1 promotes cell proliferation, migration, and invasion by downregulation of miR-143 in FTC-133 thyroid carcinoma cell line" that was published in volume 51 no. 6 (2018) (Epub May 21,2018 ) in the Brazilian Journal of Medical and Biological Research.

After the publication of this study, the corresponding author requested its retraction due to "the identification of data fabrication." The Editors decided to immediately retract this paper to avoid further damage to the scientific community.

The Brazilian Journal of Medical and Biological Research remains vigilant to prevent misconduct and reinforces the Journal's commitment to good scientific practices. We regret the unprofessional behavior of the authors involved. 


\title{
IncRNA CCAT1 promotes cell proliferation, migration, and invasion by down-regulation of $\mathrm{miR}-1 / 3$ in FTC-133 thyroid carcinoma celi $n$.
}

\author{
Tianzheng Yang ${ }^{1}$, Hongyan Zhai ${ }^{1}$, Ruihong Yan ${ }^{1}$, Zhenhu Zhou ${ }^{1}$, Lei Gao ${ }^{1}$, la Luqirı Nang ${ }^{2}$ \\ ${ }^{1}$ Department of Nuclear Medicine, Liaocheng People's Hospital / iac ong, S' ndong, China \\ ${ }^{2}$ Department of Radioimmunoassay, Liaocheng People's Hospital, ch andong, China
}

\begin{abstract}
Thyroid cancer is a common malignant tumor. Long non-coding RNA colon cance ass lated transcript 1 (IncRNA CCAT1) is highly expressed in many cancers; however, the molecular mechanism of $\mathrm{CC}$ in ancer remains unclear. Hence, this study aimed to investigate the effect of CCAT1 on human thyroid cancer cell linc ${ }^{\top} \mathrm{C}-133$. FTC-133 cells were transfected with CCAT1 expressing vector, CCAT1 shRNA, miR-143 mimic, and miR inhibitor, spectively. After different treatments, cell viability, proliferation, migration, invasion, and apoptosis were measur IV r r r the regulatory relationship of CCAT1 and miR-143, as well as miR-143 and VEGF were tested using dual-lucif reporter assay. The relative expressions of CCAT1, miR-143, and VEGF were tested by qRT-PCR. The expressions apoptosis-related factors and corresponding proteins in PI3K/AKT and MAPK pathways were analyzed using torn blot al alysis. The results suggested that CCAT1 was up-regulated in the FTC-133 cells. CCAT1 suppression decre ed F, 133 cell viability, proliferation, migration, invasion, and miR-143 expression, while it increased apoptosis and VEGK pressio CCAT1 might act as a competing endogenous RNA (ceRNA) for miR-143. Moreover, CCAT1 activated PI3K/f $T$ anc. 'AP' signaling pathways through inhibition of miR-143. This study demonstrated that CCAT1 exhibited pro-prolifere ar pro rastasis functions on FTC-133 cells and activated PI3K/ AKT and MAPK signaling pathways via down-regula for niR-143. These findings will provide a possible target for clinical treatment of thyroid cancer.
\end{abstract}

Key words: Thyroid cancer; CCAT1; miR-14 Vt PI3K/AKT pathway; MAPK pathway

\section{Introduction}

Thyroid cancer is a common endo ne sy em malignant tumor, accounting for $3 \%$ un malignant tumors (1). It can be divided it I Iw and undifferentiated (2). The fiv ar survival rate of differentiated thyroid car ould ach $90 \%$, but for the undifferentiated type is le sthan . $0 \%$ (3). Over the past few decades, the in rising globally. nough is disease has improved with early diagnos a treatmunt, the mortality rate has not declined (4) Hence is necessary to study the pathogenesis d regulatory mechanisms of thyroid cancer in order effe avely reduce mortality and improve clinical treatmen

\footnotetext{
vi the a development of tumor molecular biology, lany sonarchers have studied tumors using modern molecechnology. The findings show that tumor development invo $s$ a series of key molecules, such as cancer stem cells, long non-coding RNAs (IncRNAs), and microRNAs (miRNAs) (5-7). These molecules are important for almost
}

all cancers and are responsible for the modulation of the tumor microenvironment in malignant processes (7).

IncRNAs are a class of conserved non-coding RNA in eukaryotic cells with a length longer than $200 \mathrm{nt}$ (8). Accumulating evidence suggests that a number of IncRNAs play important roles in the development of many cancers $(9,10)$. For example, Tuo et al. reported that IncRNA UCA1 was up-regulated and could regulate cell proliferation and apoptosis in breast cancer by down-regulation of miR-143 (9). IncRNA GAS5 is low-expressed in lung cancer tissues and regulates cell proliferation and apoptosis by activating p53 and E2F1 signaling pathways (10). In addition, some IncRNA expressions could be used as markers for cancer diagnosis (11); for example, IncRNA PVT1 is an independent risk factor for hepatocellular carcinoma ( $\mathrm{HCC}$ ) recurrence (12). Furthermore, IncRNA colon cancerassociated transcript 1 (CCAT1) was first discovered in 2012 (13) and is highly expressed in many cancers, including gastric cancer, colon cancer, and HCC (14-16).

Correspondence: Ruihong Yan: <yanruihong810@126.com> 
Meanwhile, CCAT1 promotes proliferation, migration, and invasion of cancer cells inducing tumorigenesis and metastasis process. Moreover, Deng et al. (15) showed that CCAT1 boosts HCC progression via functioning as a let-7 sponge. However, the regulation and molecular mechanism of CCAT1 in the thyroid cancer remain unclear.

miRNAs are widely distributed in eukaryotes and can participate in many physiological processes, including proliferation, apoptosis, and differentiation of biological cells (5). In previous studies, miR-143 was found to be highly expressed in several cancers and was mainly identified as tumor suppressor by inhibiting tumor growth $(17,18)$. Only one study reported that miR-143 expression was decreased in thyroid cancer and B-cell malignancies (18).

Therefore, we aimed to explore the molecular mechanism of IncRNA CCAT1 to reveal its potential in thyroid cancer therapy by focusing on the regulation between CCAT1 and miR-143.

\section{Material and Methods}

\section{Cell culture}

Human follicular thyroid carcinoma cell line FTC-133 (BNCC337959) and human thyroid normal cell line Nthy-ori 3-1 (BNCC340487) were purchased from BeNa Culture Collection (BNCC; China). The cells were cultured in $ر \%$ Dulbecco's Modified Eagle's Medium (DMEM; $\mathrm{S}$ arbir China) supplemented with $100 \mathrm{U} / \mathrm{mL}$ penicillin, $1{ }^{n} 0,{ }_{1}$ streptomycin, and $10 \%$ heat-inactivated $f$ al bov. serum (FBS; all from Sigma-Aldrich, USA) cubatea in a humid atmosphere containing $5 \% \mathrm{CO}_{2}$ at $3 \%$

\section{Cell transfection}

In order to test CCAT1 expressio hort- rpin RNA (shRNA) directed against human Inch CCAT1 was ligated into the U6/GFP/Neo pl w. to become sh-CCAT1. The ful on 1 CCAT1 sequence was constructed in $\mathrm{pE}$ and $s$ called pEX-CCAT1. The plasmid carrying non arget y sequence was used as a negative contro. $C$ CAT1 that was referred to as sh-NC. miP $43 \mathrm{~m}$, inhibitor, and their respective NCs were syp red ana ansfected into FTC-133 cells in this study (vene, rma). Following the manufacturer's instructio , cell trans ction was performed using Lipofectam 000 reagent (Thermo Fisher Scientific, USA). rably ansfected cells were selected by the cr mea. ontaining $0.5 \mathrm{mg} / \mathrm{mL}$ G418 (Sigma-Aldrich, SA) After auproximately 4 weeks, G418-resistant FTC2 exp ments.

\section{Cell viability assay}

FTC-133 cells were seeded in 96-well plates with $2 \times 10^{3}$ cells/well and assessed by Cell Counting Kit-8 (CCK-8; Dojindo Molecular Technologies, USA). Briefly, $10 \mu \mathrm{L}$ of CCK-8 solution was added to each well, and the cultures were then incubated for $1 \mathrm{~h}$ at $37^{\circ} \mathrm{C}$ in humidified $95 \%$ air and $5 \% \mathrm{CO}_{2}$. The experiment was repeat three times. Absorbance was measured at $450 \mathrm{n}$ usi' $\mathrm{y}$ a Microplate Reader (Bio-Rad, Hercules, USF

\section{Cell proliferation assay}

FTC-133 cells were seeded in 96 plat with $2 \times 10^{3}$ cells/well. Cell proliferation is e d using BrdU Cell Proliferation Assay Kit , igma-Aldric, following the manufacturer's instructions. brief, E IU was added to each well, and cultures $37^{\circ} \mathrm{C}$. Cells were then asho in pnosphate buffered saline (PBS) twice an red with ethanol for $10 \mathrm{~min}$. Each experiment wis ro ated at least three times independently. A rbance $s$ measured at $450 \mathrm{~nm}$ using a Microp' a f ader (Bio-Rad).

\section{Cell migration a. invasion assay}

Cell tion wo determined using a modified twochamber etr th a pore size of $8-\mu \mathrm{m}$ membranes. FTC-133 $\left(2 \times 10^{4} / \mathrm{ml}\right)$ were suspended in $100 \mu \mathrm{l}$ of serum-free MEM medium and seeded on the upper nartment of 24-well Transwell culture chamber (Millipore, SA). DMEM $(500 \mu \mathrm{L})$ medium including $10 \%$ fetal bovine serum (FBS; Sijiqing, China) was added to the compartment. After incubation for $24 \mathrm{~h}$ at $37^{\circ} \mathrm{C}$ in $5 \% \mathrm{CO}_{2}$ atmosphere, all cells were fixed with $95 \%$ ethanol $30 \mathrm{~min}$. Non-traversed cells were removed from the upper surface of the filter carefully with a cotton swab; the traversed cells on the lower side of the filter were stained with $0.5 \%$ crystal violet (Solarbio, China) for $30 \mathrm{~min}$ and counted under a microscope (Leica Microsystems, Germany). The experiment was repeated three times.

Cell invasion was measured using 24-well Millicell ${ }^{\mathbb{R}}$ Hanging Cell Culture Inserts with $8-\mu \mathrm{m}$ PET membranes (Millipore). FTC-133 cells $\left(2 \times 10^{4} / \mathrm{mL}\right)$ in $200 \mu \mathrm{L}$ serumfree DMEM medium were plated onto $\mathrm{BD} \mathrm{BioCoat}^{\mathrm{TM}}$ Matrigel $^{\mathrm{TM}}$ Invasion Chamber (BD Biosciences, USA), while DMEM medium containing $10 \%$ FBS was added to the lower chamber. After processing the invasion chambers for $48 \mathrm{~h}$ at $37^{\circ} \mathrm{C}\left(5 \% \mathrm{CO}_{2}\right)$ in accordance with the manufacturer's protocol, the non-invading cells were removed with a cotton swab. The invading cells were fixed in $100 \%$ methanol for $30 \mathrm{~min}$, stained with $0.5 \%$ crystal violet solution for $30 \mathrm{~min}$, and then counted microscopically. The experiment was repeated three times.

\section{Apoptosis assay}

Apoptotic assays were performed using Annexin V-FITC/PI Apoptosis Detection Kit (Sigma-Aldrich). In brief, stable FTC-133 cells $\left(2 \times 10^{4} / \mathrm{mL}\right)$ were washed in cold PBS three times and stained in $200 \mu \mathrm{L}$ of binding buffer including $10 \mu \mathrm{L}$ Annexin V-FITC and $5 \mu \mathrm{L}$ of PI in the presence of $50 \mu \mathrm{g} / \mathrm{mL}$ RNase A (Sigma-Aldrich), and then incubated for $1 \mathrm{~h}$ at room temperature in the dark. Flow cytometry analysis was done using a FACScan 
(Beckman Coulter, USA). The data were analyzed by using FlowJo software (Treestar, Inc., USA).

\section{Dual-luciferase reporter assay}

The fragment from CCAT1 was amplified by PCR and then cloned into a pmirGLO dual-luciferase miRNA Target Expression Vector (Promega, USA). Then, miR-143 mimics were individually co-transfected with the reporter vector CCAT1-wild-type (CCAT1-wt) or CCAT1-mutatedtype (CCAT1-mt) into FTC-133 cells. The fragment from VEGF $3^{\prime}$ UTR was amplified by PCR and then cloned into a pmirGLO dual-luciferase miRNA Target Expression Vector (Promega). miR-143 mimics were individually cotransfected with the reporter vector VEGF 3'UTR-wild-type (VEGF $3^{\prime} U T R$-wt) or VEGF $3^{\prime} U T R$-mutated-type (VEGF $3^{\prime}$ UTR-mt) into FTC-133 cells. Dual-luciferase ${ }^{\circledR}$ Reporter Assay System Protocol (Promega) was used to measure the luciferase activity after $48 \mathrm{~h}$ of cell transfection and collection. The experiment was repeated three times independently.

\section{Quantitative real-time polymerase chain reaction (qRT-PCR)}

According to the manufacturer's instructions, total RNA was extracted from FTC-133 cells using Trizol reagen ${ }^{+}$ (Life Technologies Corporation, USA). The expression level of CCAT1 was tested using One Step SY ${ }^{\circledR}$ PrimeScript ${ }^{\mathrm{R}}$ PLUS RT-RNA PCR Kit (TaKaRa $P$ nology, China). The Taqman MicroRNA Reverse scription Kit and Taqman Universal Master \& II (b from Applied Biosystems, USA) were user to tect the level of miR-143 expression. The GAPDH and were used in this study for normalizing $C$. . and min-143 levels. The sequences of qRT-PCR pri ers wer as follows: IncRNA CCAT1, 5'-AGAAACACT, CACC ACGC-3' (Forward) and 5'-CTTAACA -GGCA. IAATCT-3' (Reverse); miR-143, 5'-AAGC TCAAGGTTTGGT CCT-3 (Forward) and 5'-CTC $C$ GUAAGATGGACA CACTGG-3' (Reverse) , 5 GCTTCGGCAGCACA TATACTA-3' (Forwar, ar 5'-C CTTCACGAATTTGC GTGTCA-3' (Rever , 5'-TGTTGCCATCAAT GACCCCTT-3' orwa. and 5'-CTCCACGACGTACT CAGCG-3' (P se); sh- CAT1, 5'-CCTGGCCCTCTC ATCAGAGAOITG, TTA-3'; miR-143 mimic, 5'-GGUG CAGUG JGCAUCL UGGU-3' (mimics sense) and 5'-CAG SAU' CAGCACUGCACCUU-3' (mimics antisense); and $\mathrm{mi} \cdot 3$ in $^{\prime}$ itor, 5'-ACCAGAGAUGCAGCACUG $C$, nanges were calculated by the relative dant cation $\left(2^{-\Delta \Delta \mathrm{Ct}}\right)$ method (19).

\section{W. rn blot analysis}

RIn A lysis buffer (Beyotime Biotechnology, China) supplemented with protease inhibitors (Roche, China) was used to extract the proteins for western blot analysis. Proteins were quantified using the $\mathrm{BCA}^{\mathrm{TM}}$ Protein Assay Kit (Pierce, Appleton, USA) following the manufacturer's protocol. Then, proteins (30 $\mu \mathrm{g} / \mathrm{sample}$ ) were loaded, electrophoresed by $10 \%$ sodium dodecyl sulfate-polyacrylamide gel electrophoresis (SDS-PAGE), and transferred to the $p$ vinylidene difluoride (PVDF) membranes. The prima anti' ${ }^{\prime}$ dy of VEGFA (ab46154), Bcl-2 (ab32124), Bax b? 003) pro-caspase-3 (ab32499), cleaved-caspase-3 ( 30 , pro-caspase-9 (ab135544), cleaved-carnase-9 (ab__4), PI3K p85 (ab191606), p-P13K p85 (c 182651 AKT (ab8805), p-AKT (ab38449), MAPKA nase (31531), p-MAPKAP Kinase 2 (ab131504 and GAPDi. (ab9485) were obtained from Abcam (Chin prepa d in $5 \%$ blocking buffer at a dilution of 100 in sated with the membrane for $2 \mathrm{~h}$ at $4^{\circ} \mathrm{C}$ rası. twice in PBS, and then cultivated with second antibou, $1: 1000)$ marked by horseradish peroxidas for at room temperature. Immobilon Western che "umines $\mathrm{HRP}$ substrate $(200 \mu \mathrm{L}$; Millipore) was ? ded cover the membrane surface, the signals were tur the intensity of the bands was quantified using $\mathrm{h}$. qe $\mathrm{Lab}^{\mathrm{TM}}$ software (Bio-Rad).

\section{Statistic. an}

The re are reported as means \pm SD. Statistical analyses we performed using SPSS 19.0 statistical soft(IBM Corporation, USA). The P-values were calcula using a one-way analysis of variance (ANOVA). $\mathrm{P}<0.1$ indicated a statistically significant result.

\section{Rtoults}

CCAT1 overexpression enhanced cell viability, proliferation, migration, and invasion in FTC-133 cells

In order to assess the effect of CCAT1 on thyroid carcinoma cells, we first detected the expression level of CCAT1 in different cell lines using qRT-PCR, and found that CCAT1 was up-regulated in thyroid carcinoma cell line FTC-133 compared with human thyroid normal cell line Nthy-ori 3-1 $(P<0.01$, Figure $1 \mathrm{~A})$. The transfection efficiency of CCAT1 overexpression and suppression were examined in FTC-133 cells. As shown in Figure 1B and C, CCAT1 expression was significantly down-regulated in the sh-CCAT1 group and up-regulated in the pEX-CCAT1 group (both $\mathrm{P}<0.01$ ). The results of CCK-8, BrdU, Transwell, and invasion assay (Figure 2A and D) showed that cell viability, proliferation, migration, and invasion were all increased when CCAT1 was overexpressed (all $P<0.05)$. However, suppression of CCAT1 displayed the opposite results; that is, cell viability, proliferation, migration, and invasion were greatly reduced (all $P<0.05$ ). Subsequently, apoptosis and the expressions of apoptosis-related proteins were detected using flow cytometry analysis and western blot, respectively. The results suggested that apoptosis was significantly elevated by CCAT1 knockdown $(\mathrm{P}<0.001)$. The expression of $\mathrm{Bcl}-2$ was down-regulated and Bax, cleaved-caspase-3, and cleavedcaspase-9 expressions were up-regulated in sh-CCAT1 group (Figure 2E and F). Moreover, CCAT1 overexpression had little effect on apoptosis. 

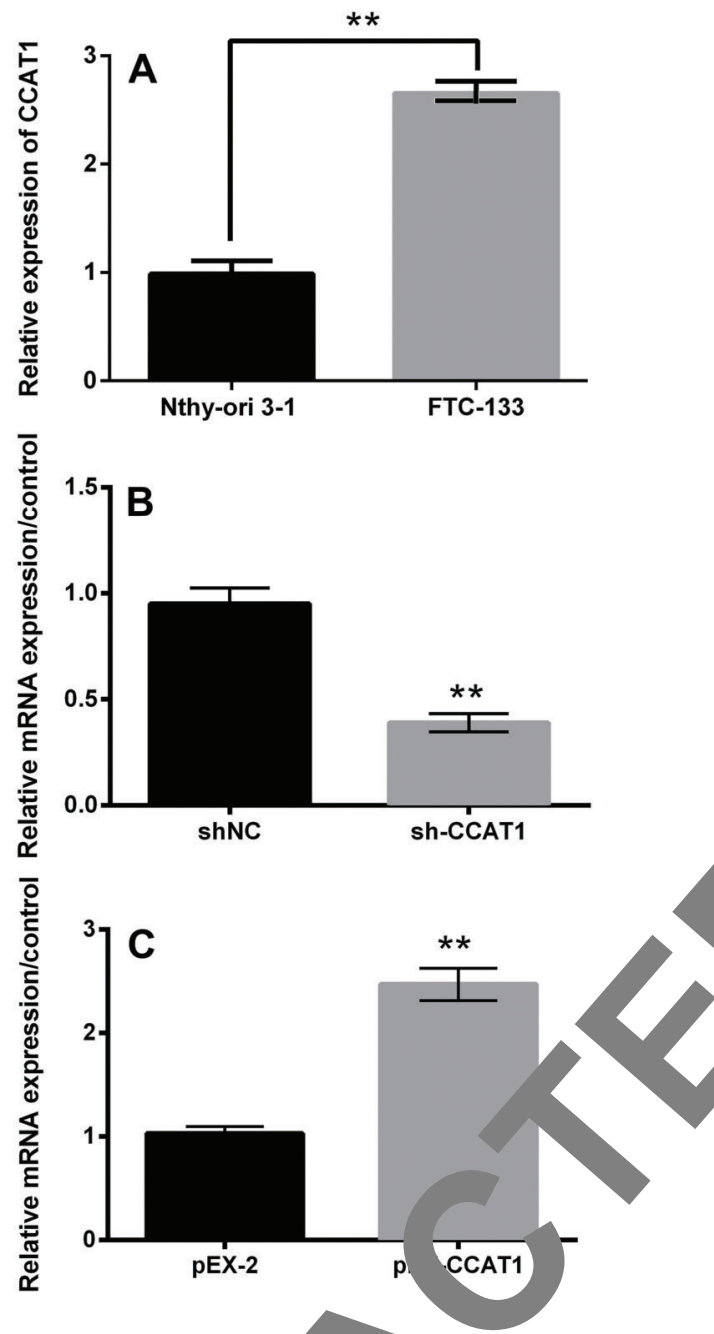

Figure 1. Expression of CCAT1 FIV cells. Cells were transfected with CCAT1 expressin or or CCAT1 shRNA. $A$, The mRNA level of $C$ vas $c$ ected using qRT-PCR in Nthy-ori 3-1 cells and $r$ c-13 cells. and $C$, The expression level of CCAT1 suppre ox expression were tested by using qRT-PCR in $C$-1 Olls. NC: negative control. Data are reported as mea $S D$. ${ }^{* *} 01$ (ANOVA).

CCAT' ver pression promoted vascular endothelial growth or ( $Y$ GF) expression in FTC-133 cells via d egu of miR-143

Tr requlatory relationship between CCAT1 and miR-143 using QRT-PCR and dual-luciferase reporter ass Thus, the expressing vector and shRNA of CCAT1 were ansfected into FTC-133 cells to overexpress and silence CCAT1 expression, respectively. The expression of miR-143 was clearly up-regulated by CCAT1 suppression and down-regulated by CCAT1 overexpression in FTC-133 cells $(\mathrm{P}<0.05$ or $\mathrm{P}<0.01$; Figure $3 \mathrm{~A})$. Figure $3 \mathrm{~B}$ showed that CCAT1 had binding sites for miR-143, which might better explain the negative regulatory relationship between CCAT1 and miR-143. Therefore, we suspected that $\mathrm{CCA}^{\top}>$ might be working as a competitive endogenous RNA RN/ for miR-143. To verify this hypothesis, dual-lucife assay was performed. The relative luciferase à vity FTC-133 cells that were co-transfected with CC- - wt and miR-143 mimic was lower than the co-trar fected with CCAT1-mt and NC $(P<0.05$ are lown in Figure $3 D$ and $E$, the results of $q$ r $-P C R$ and western blot displayed that CCAT1 knockdown crease he expression of VEGF, while the opposite ults ro served in pEXCCAT1 group $\left(\mathrm{P}<0.05 \mathrm{O}^{\prime}<0\right.$ ). To turther explore the relationship between m 43 and GF in FTC-133 cells, we analyzed VEGF en,ress in cells transfected with miR143 mimic or inhir. As sh $\lambda$ in Figure 3F, efficiency of miR-143 up- gula $n$ and inhibition was confirmed by using qRT-PC d H suggested that the mRNA and protein leve. of VEGF were reduced in miR-143 mimic-tre cells, h 2 miR-143 inhibitor up-regulated the expressic of $\rightarrow(\mathrm{P}<0.05$ or $\mathrm{P}<0.01)$. As shown in Figure 3l, t was a binding site for miR-143 in VEGF. The relative lucit se activity in FTC-133 cells co-transfected VEGF 3UTR-wt and miR-143 mimic was lower than cells transfected with VEGF 3UTR-mt and NC $(\mathrm{P}<0.05$, Figure 3J). Therefore, miR-143 and VEGF exhibited the $\checkmark$ ve regulatory relationship, which explained the positive regulation of CCAT1 on VEGF.

CCAT1 overexpression increased cell viability, proliferation, migration, and invasion in FTC-133 cells by down-regulating miR-143 expression

The effects of CCAT1 in combination with miR-143 were further studied on FTC-133 cells. CCAT1 overexpression plus miR-143 overexpression decreased cell viability and proliferation relative to only CCAT1 overexpression (both $\mathrm{P}<0.05$; Figure $4 A$ to $D$ ). Cell viability and proliferation were increased after CCAT1 suppression plus miR-143 knockdown relative to only CCAT1 suppression (both $\mathrm{P}<0.05$ ). Similarly, miR-143 overexpression inhibited the increases of cell migration and invasion induced by CCAT1 overexpression; on the contrary, miR143 knockdown enhanced the reduction of migration and invasion induced by CCAT1 suppression (all $\mathrm{P}<0.05$; Figure $5 A$ to $D)$. In addition, we also detected expressions of apoptosis and apoptosis-related proteins by the treatments of miR-143 silence combined with CCAT1 suppression. As shown in Figure $5 \mathrm{E}$ and $\mathrm{F}$, apoptosis, Bax, and cleaved caspase-3/9 expressions were significantly reduced; $\mathrm{Bcl}-2$ expression was simultaneously increased in sh-CCAT1 + miR-143 inhibitor group compared with sh-CCAT1 + NC group $(\mathrm{P}<0.05)$.

CCAT1 overexpression activated PI3K/AKT and MAPK signaling pathways via down-regulation of miR-143

The expressions of the proteins associated with PI3K/ AKT and MAPK signaling pathways were assessed using 

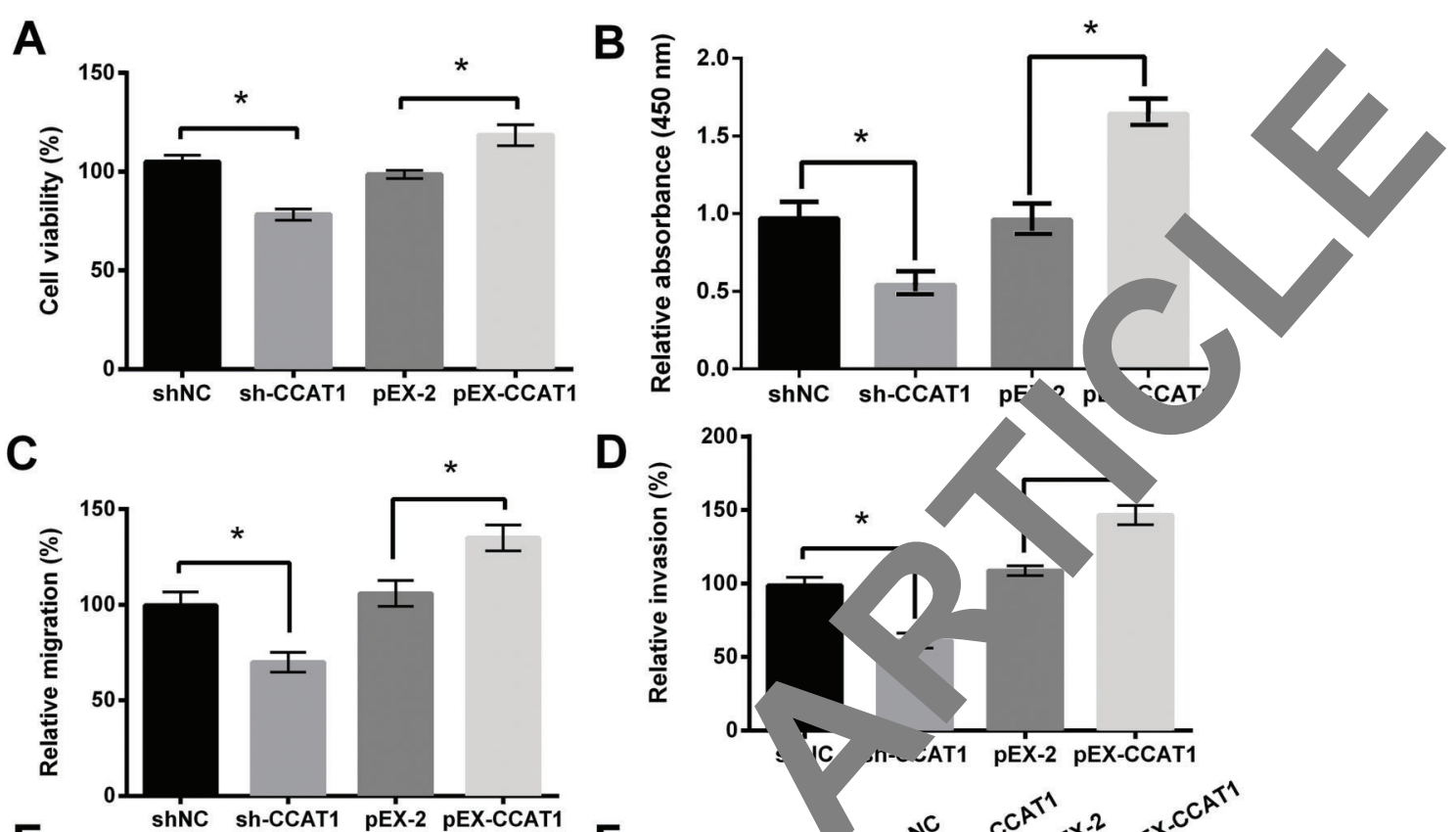

D

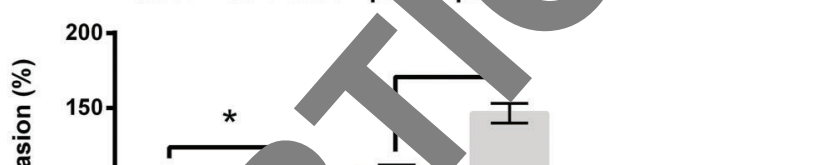

E

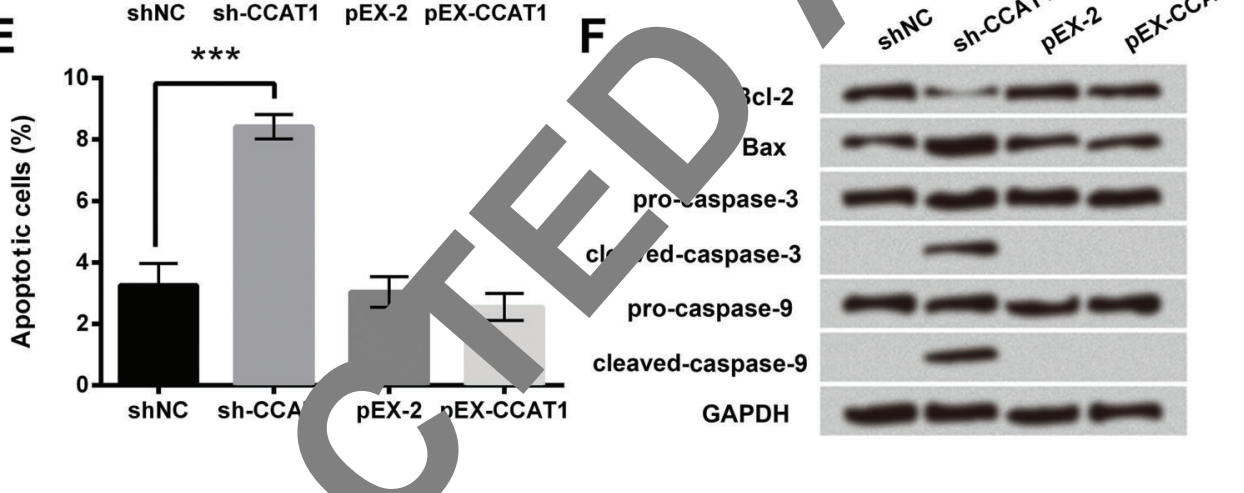

Figure 2. CCAT1 increased cell yimility, prom .on, migration, and invasion in FTC-133 cells. Cells were transfected with CCAT1 expressing vector or CCAT1 shRN Cell viability, proliferation, migration, invasion, and apoptosis were measured using CCK-8, BrdU assay, Transwell assay, invas ac $\lambda y, \ldots$ id flow cytometry analysis, respectively. $F$, The expressions of apoptosis-related proteins were detected using wester $-10 t$ an is. NC: negative control. Data are reported as means $\pm S D$. ${ }^{*} P<0.05$; ${ }^{* \star *} P<0.001$ (ANOVA).

western blot an ysis. e results (Figure 6A and B) displayed tha' levels i p-P13K p85, p-AKT, and p-MAPKAP knase vere all obviously up-regulated after CCAT1 crexpressic, and then miR-143 overexpression in sted rese increases. Conversely, CCAT1 knockdown do egule d p-P13K, p85, p-AKT, and p-MAPKAP $\mathrm{Ki} 2 \mathrm{C}$, 2 while their expressions were further crea ed after miR-143 suppression.

\section{D. ussion}

Thyroid cancer is characterized by high morbidity and rapid growth in China (20). IncRNAs can participate in the regulation of cell proliferation, migration, and apoptosis by controlling the expression of downstream miRNAs $(21,17)$. Therefore, we studied the regulatory mechanism of IncRNA CCAT1 on thyroid cancer cell line FTC-133. CCAT1 was closely related with colon cancer genesis, and down-regulation of miR-143 was a well-known potential marker for colon cancer and played an important role in carcinogenesis $(22,23)$. Therefore, we analyzed the binding site of CCAT1 and miR-143. As CCAT1 was upregulated in $\mathrm{FTC}-133$ cells, the regulatory relationship of CCAT1 and miR-143 in FTC-133 cells were analyzed and the effects of CCAT1-miR-143 axis on FTC-133 cells were also explored. Furthermore, the mechanism of CCAT1 was investigated by detecting activations of PI3K/AKT and MAPK signaling pathways after altering expressions of CCAT1 and miR-143.

Our study suggested that CCAT1 might act as a competing endogenous RNA (ceRNA) for miR-143. CCAT1 overexpression up-regulated miR-143-mediated 
A

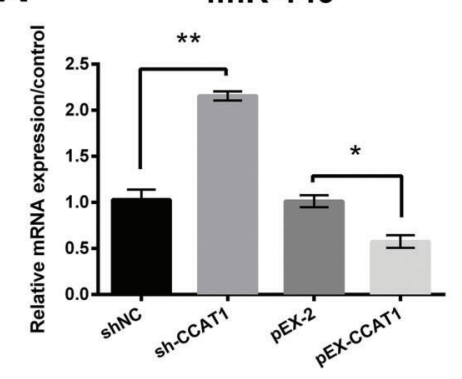

B

CCAT1-wt 5'-GAAACACAGTGCACAACAAAT-3' 1sa-miR-143-3p 3'-CUCGAUGUCACGAAGUAGAGU-5' CCAT1-mt 5'-ACAACCACCACAACAACAAAT-3
D

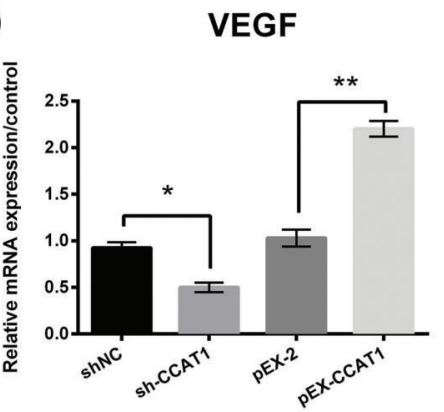

E

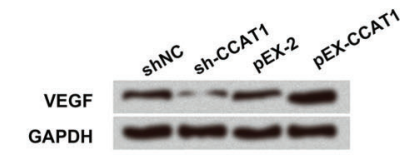

G

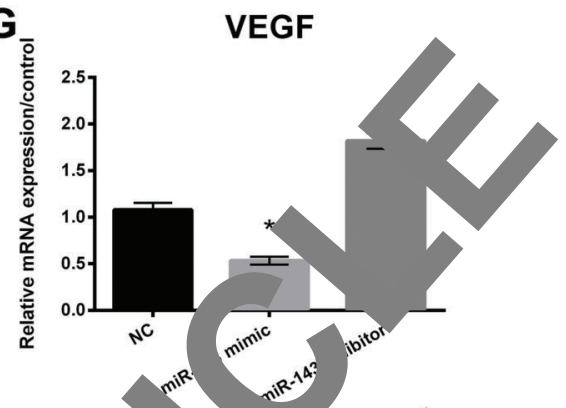

H
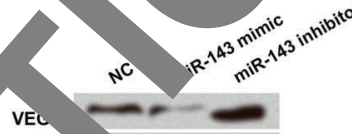

I

GAPDH
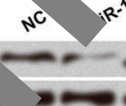

$R^{-1 x^{3}} m$

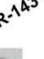

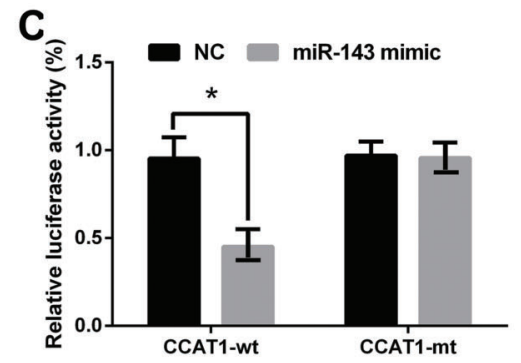

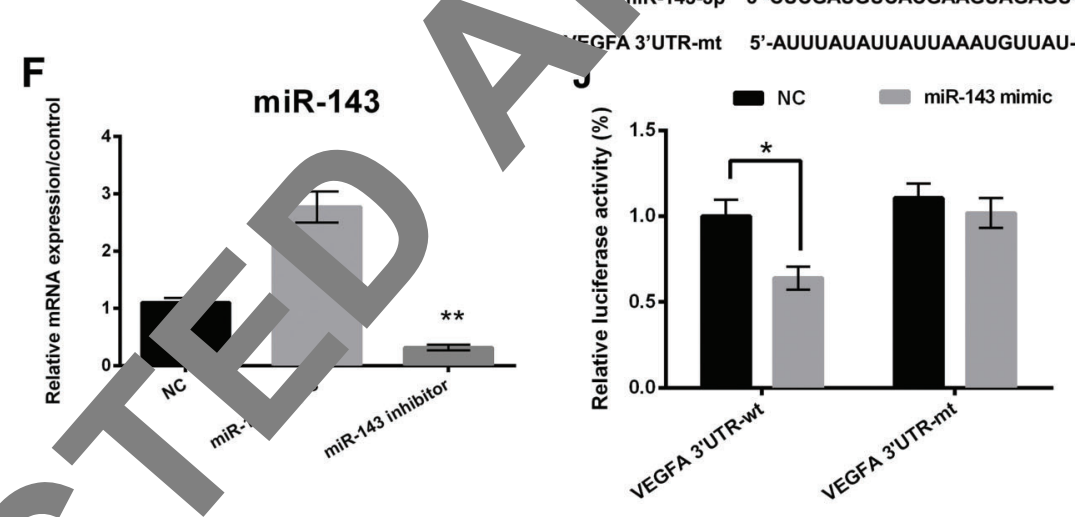

Figure 3. CCAT1 promoted the up-regulat of VEC via inhibition of miR-143. FTC-133 cells were transfected with CCAT1 expressing vector, CCAT1 shRNA, miR-143 mimic, or $\mathrm{h}$ 143. ibitor. A, mRNA expression of miR-143 was detected in FTC-133 cells using qRTPCR. B, The predicated miR-14 inding slu C CAT1 (CCAT1-wt) and the designed CCAT1-mt are indicated. C, The binding relationship between CCAT1 and cells were detected using qRT-PC, $F$ ne srotein level of VEGF with sh-CCAT1 or pEX-CCAT1 was analyzed using western blot analysis. $F, G$, mRNA level miR-i and VEGF with miR-143 mimic or inhibitor were tested using qRT-PCR. $H$, The protein level of VEGF with miR-143 mim or it bitor re detected using western blot analysis. I, The predicted miR-143 binding site of VEGF $3^{\prime} U T R$ (VEGF 3'UTR-wt) and des assessed using dua ${ }^{\prime \prime} u \mathrm{Cl}$ e reporer assay. NC: negative control. Data are reported as means $\pm \mathrm{SD}$. ${ }^{*} \mathrm{P}<0.05$; ${ }^{* *} \mathrm{P}<0.01$ (ANOVA).

VEGF ey ession, inc ating that CCAT1 might promote angion esis 1 thyroid carcinoma. CCAT1 overexpression enhance il vir ity, proliferation, migration, and invasi we educed apoptosis by down-regulation of R-1 3. In audition, we also found that CCAT1 activated 2' mir 43 expression.

Ino NNA CCAT1 is a non-coding RNA with the length of $2628 \mathrm{nt}$ and originally found in colon cancer (13). A large number of studies have shown that knockdown of CCAT1 significantly inhibited cell proliferation and migration and promoted apoptosis in many cancers, including glioma (21), prostate cancer (24), and HCC (15), suggesting that
CCAT1 was an oncogene. In our study, we first found that CCAT1 was overexpressed in FTC-133 cells. Further results showed that CCAT1 overexpression increased cell viability, proliferation, migration, and invasion, but obviously reduced apoptosis of FTC-133 cells. These findings were consistent with previous studies $(15,21,24)$, implying that CCAT1 could promote cancer growth in FTC133 cells.

miR-143 has been reported to decrease prostate cancer cells' proliferation and migration (25). Moreover, a previous study reported that miR-143 is down-regulated in thyroid cancer (18). However, the results of our study revealed that overexpression of miR-143 inhibited 
A
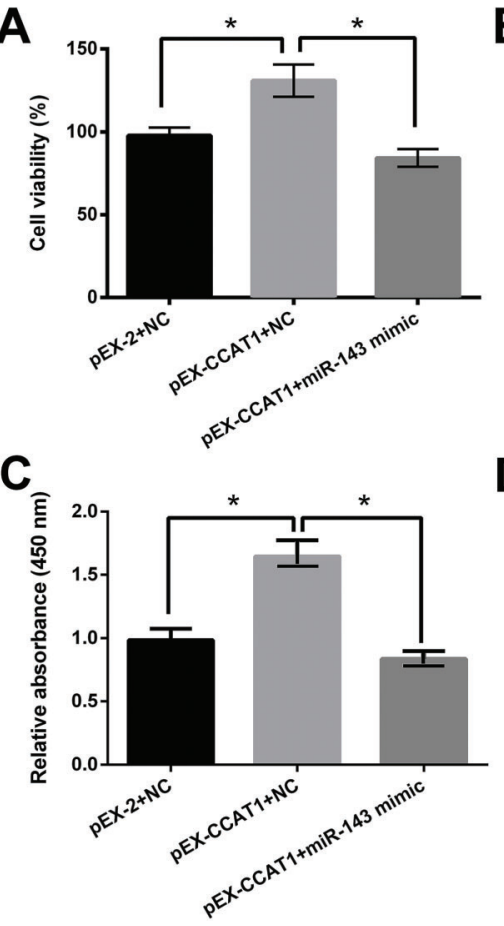

B

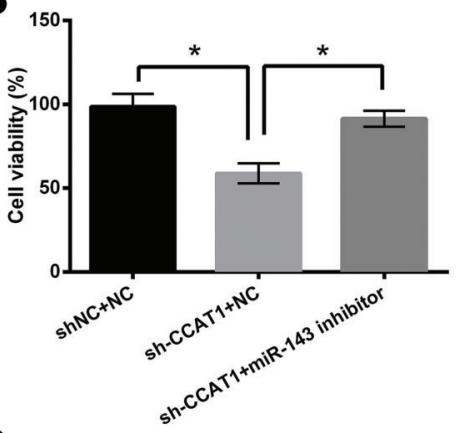

Figure 4. CCAT1 enhanced cell viability and proliferation via the inhibition of miR- 3 . FTC133 cells were transfected with $C C, 1$ e essing vector, CCAT1 shRNA, miR-1 miR-143 inhibitor $A$ and $B$, Cell vit $C$ and $D$, proliferation were measured in $\mathrm{F}$, 33 cells using CCK-8 and Brdc say, resp rctively. NC: negative control. Data re ted as means $\pm \mathrm{SD}$. ${ }^{*} \mathrm{P}<0.0$,

D

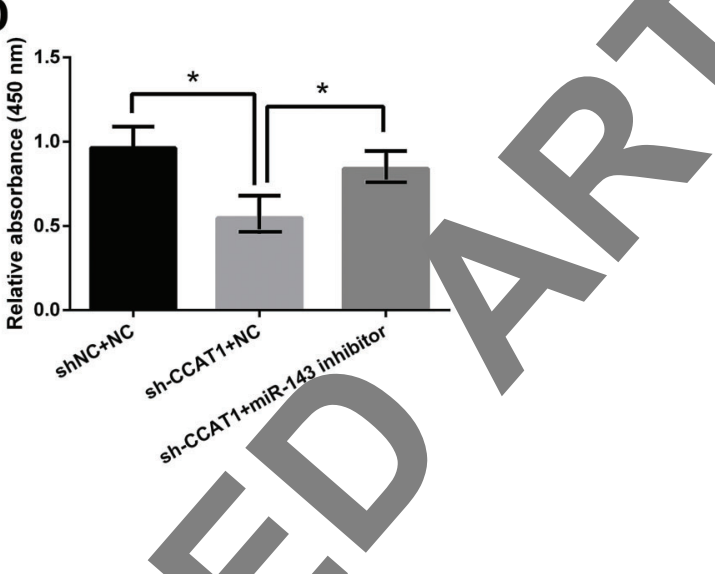

increases of cell viability, proliferation, migration and the reduction of apoptosis in FTC-133 s. The fore, we speculated that miR-143 was a tho. uppressor for thyroid cancer and upstream remulated $4 T 1$. Recent studies have demonstrated al incRNAs runction as ceRNA by sponging miRN, to res ate gene expression at a post-transcriptional lev 26 ). F instance, CCAT1 could competitively ind mik_ -5p through intracellular "sponge-like" ac Ir. and promote the expression of target genes, lea 0 the proliferation of bladder cancer cells ar asio of blood vessels (27). Thus, we explored re llatory relationship between CCAT1 and miR-14 CCAT1 overexr ssion wn-regulated the expression of miR-143. T a was a c.nding site of miR-143 in the sequence of $\mathrm{CCA}$. Then, relative luciferase activity was low in cells co cransfected with CCAT1-wt and miR-1 mir C. Considering the context, we deduced that CCAT1 $\mathrm{d}$ ar as a molecular sponge in regulating th ogic retions of miR-143. In addition, VEGF is n im artant factor in mediating angiogenesis, which can ote tru mitosis of vascular endothelial cells and the gro. of tumor blood vessels (28). Related evidence has showr that IncRNAs and miRNAs regulate the expression of VEGF in cancers (28-30). In the current study, we found that CCAT1 positively and miR-143 negatively regulated VEGF expression. Further, the mRNA and protein level of VEGF were increased with CCAT1 verexpression or miR-143 suppression. Importantly, there was a binding site of VEGF in the sequence of miR-143 and the dual-luciferase reporter assay further confirmed their positive regulatory relationship. Therefore, VEGF also plays an important role in the study of thyroid cancer.

Pagliuca et al. (31) reported that Kirsten rat sarcoma 2 viral oncogene homolog (KRAS) and v-Raf murine sarcoma viral oncogene homolog B1 (BRAF) were targeted by miR-143. The reduction of the expressions of these proteins affected cell signaling pathways involved in transformation. Moreover, the primary mediators of miR143 in inhibiting tumors are genes belonging to the growth factor receptor-mitogen-activated protein kinase (MAPK) network. Wang et al. (32) showed that miR-143 overexpression inhibited PI3K/AKT signaling pathway in glioma and other RAS-driven cancers. Hence, we focused on P13K/AKT and MAPK pathways to explain the effect of CCAT1 on FTC-133 cells. P13K/AKT pathway is the central regulator of cell growth, proliferation, apoptosis, and metabolism (33). MAPK is a primary pathway for signal transduction of vascular endothelial cells (34). Recently, extensive research has shown that the activated P13K/AKT and MAPK signaling pathways could promote tumor cell proliferation, invasion, and migration and reduce apoptosis (34-36). Our results suggested that CCAT1 overexpression increased the expression of proteins associated with these pathways, whereas miR-143 

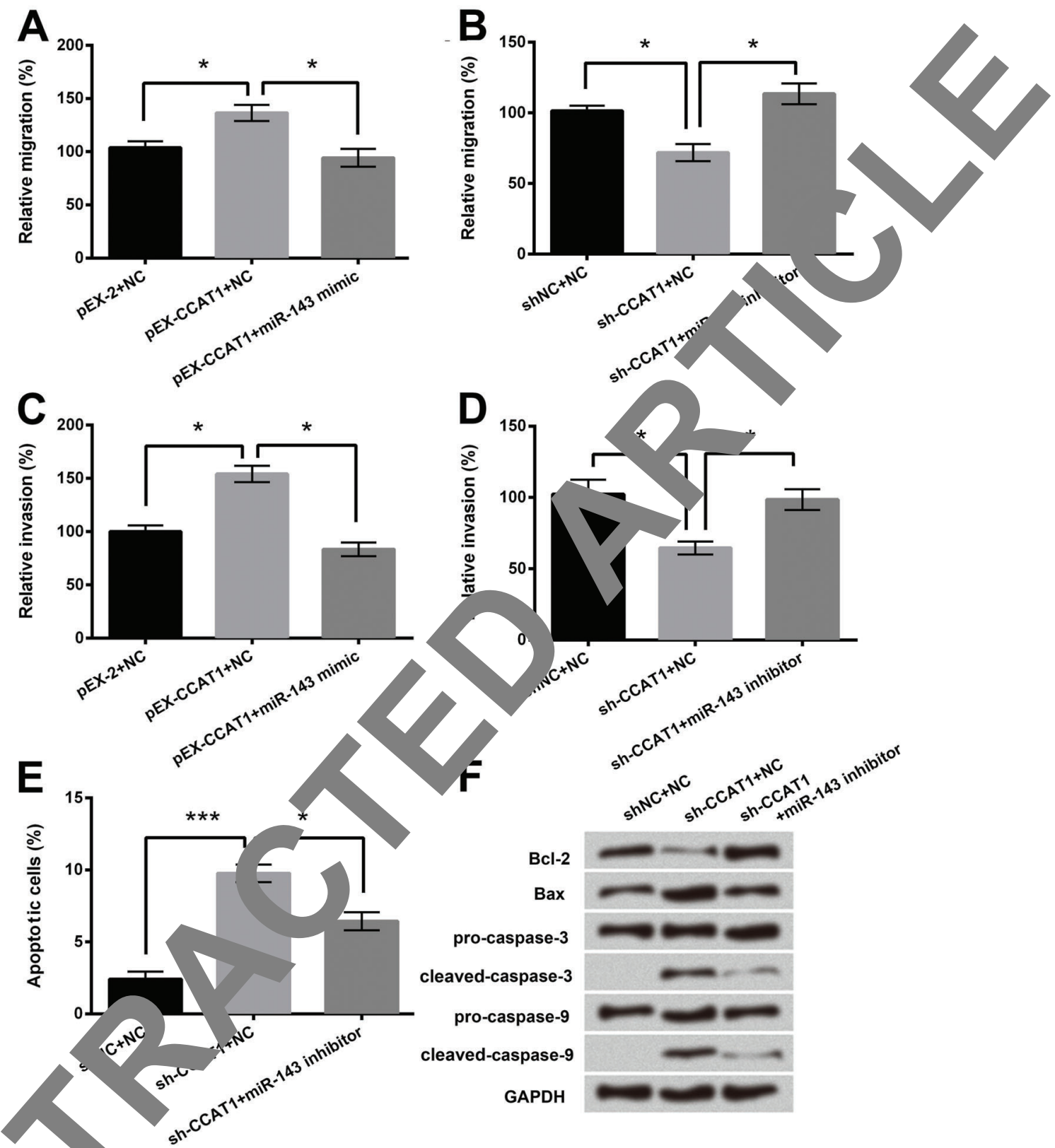

Figure CC 1 enhanced cell migration and invasion via the inhibition of miR-143. FTC-133 cells were transfected with CCAT1 expressi. tor, $\triangle$ AT1 shRNA, miR-143 mimic, or miR-143 inhibitor. $A$ and $B$, Cell migration, $C$ and $D$, invasion, and $(E)$ apoptosis we eas $\mathrm{j}$ TC cells using Transwell assay, invasion assay, and flow cytometry analysis, respectively. $F$, The expressions of spto s-rela proteins were detected using western blot analysis. NC: negative control. Data are reported as means $\pm S D$. ${ }^{*} P<0.05$, ${ }^{*} \mathrm{P}$ - 2 MNOVA).

overexpression inhibited these effects. CCAT1 could activate $\mathrm{PI} 3 \mathrm{~K} / \mathrm{AKT}$ and MAPK signaling pathways by inhibiting miR-143 expression.

In summary, our study demonstrated that CCAT1 exhibited a cancer-promoting function potentially via down-regulation of miR-143 and activation of PI3K/AKT and MAPK signal pathways in FTC-133 cells. Hence, this study might provide a basis for further study of the mechanism of IncRNA CCAT1 and a possible target for the clinical treatment of thyroid cancer. 


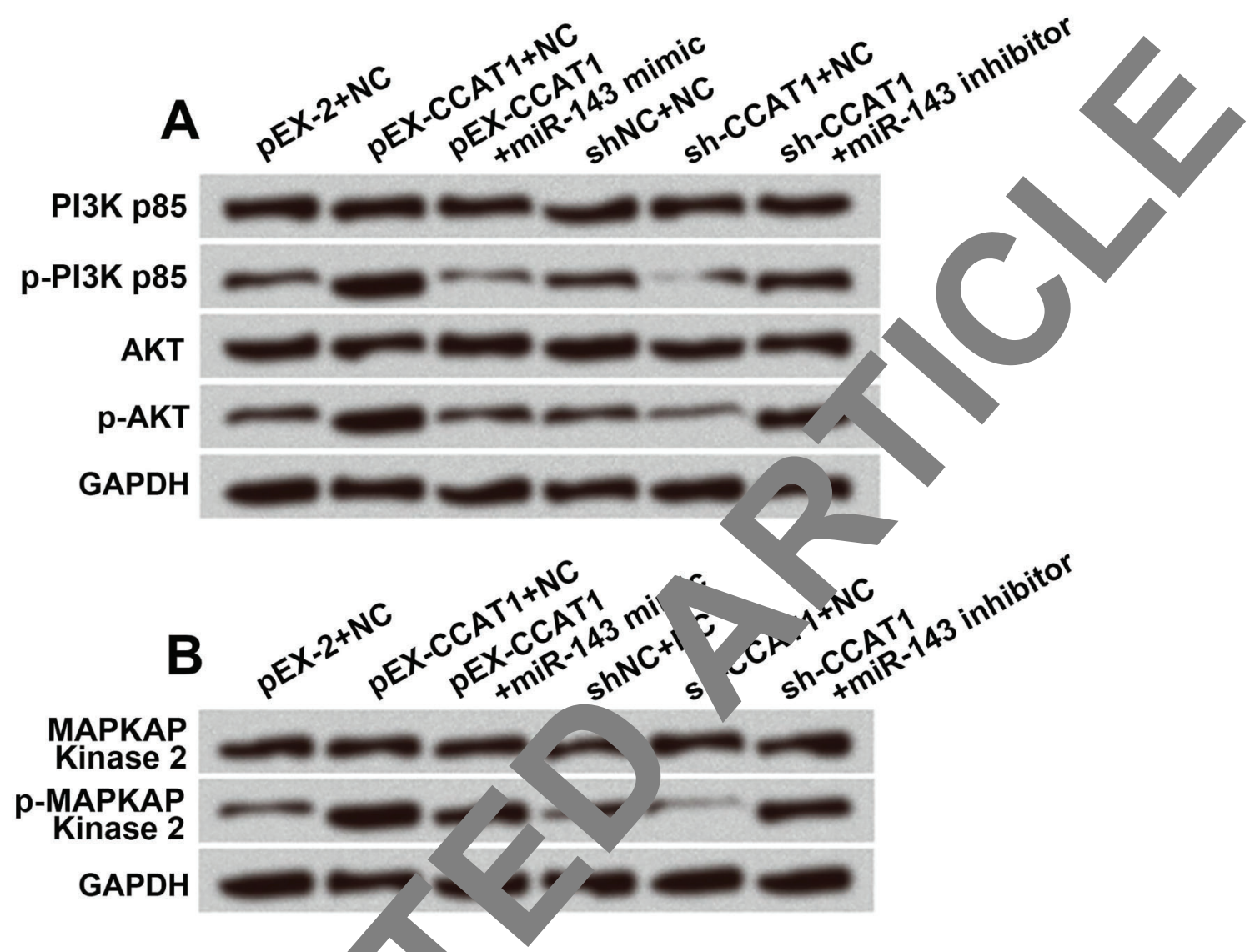

Figure 6. CCAT1 activated PI3K/AKT and MAPK signalin athways via the inhibition of miR-143. FTC-133 cells were transfected with CCAT1 expressing vector, CCAT1 shRNA, $\quad 43$ mimic, $c$ miR-143 inhibitor. The expressions of the main factors in $A, \mathrm{PI} 3 \mathrm{~K} / \mathrm{AKT}$ and $B$, MAPK signaling pathways were analy: $d$ in FTC 133 cells using western blot analysis. NC: negative control.

\section{References}

1. Siraj AK, Hussain AP- '-Ras d M, Ahmed M, Bavi P, Alsobhi SA, et al. 5 , ne lation f TMS1 gene sensitizes thyroid cancer $c$ to Endocrinol $\mathrm{Me}^{-b}$ a 96: E215-E224, doi: 10.1210/jc. 2010-0790.

2. Sipos JA iv aferri EL. Thyroid cancer epidemiology and pr anostic $h$ bles. Clin Oncol (R Coll Radiol) 2010; 22: ? -404, doi: 1u 016/j.clon.2010.05.004.

3. Ni' orov MN, Tseng GC, Steward D, Diorio D, Nikiforov YE. oRN expression profiling of thyroid tumors: biovical $;$ ance and diagnostic utility. J Clin Endocrinol $\Lambda$ tab 20u, 93: 1600-1608, doi: 10.1210/jc.2007-2696.

ra C, Malvezzi M, Bosetti C, Garavello W, Bertuccio , Levi $F$, et al. Thyroid cancer mortality and incidence: Jobal overview. Int J Cancer 2015; 136: 2187-2195, dor: $10.1002 /$ ijc.29251.

5. Garzon R, Calin GA, Croce CM. MicroRNAs in Cancer. Annu Rev Med 2009; 60: 167-179, doi: 10.1146/annurev. med.59.053006.104707.

6. Rinn JL, Kertesz M, Wang JK, Squazzo SL, Xu X, Brugmann $S A$, et al. Functional demarcation of active and silent chromatin domains in human HOX loci by noncoding RNAs. Cell 2007; 129: 1311-1323, doi: 10.1016/j.cell.2007.05.022.

7. Catana CS, Pichler M, Giannelli G, Mader RM, BerindanNeagoe I. Non-coding RNAs, the Trojan horse in two-way communication between tumor and stroma in colorectal and hepatocellular carcinoma. Oncotarget 2017; 8: 29519-29534, doi: 10.18632/oncotarget.15706.

8. Yang F, Yi F, Zheng Z, Ling Z, Ding J, Guo J, et al. Characterization of a carcinogenesis-associated long non-coding RNA. RNA Biol 2012; 9: 110-116, doi: 10.4161/rna.9.1.18332.

9. Tuo $\mathrm{YL}$, Li XM, Luo J. Long noncoding RNA UCA1 modulates breast cancer cell growth and apoptosis through decreasing tumor suppressive miR-143. Eur Rev Med Pharmacol Sci 2015; 19: 3403-3411.

10. Shi X, Sun M, Liu H, Yao Y, Kong R, Chen F, et al. A critical role for the long non-coding RNA GAS5 in proliferation and apoptosis in non-small-cell lung cancer. Mol Carcinog 2015; 54 Suppl 1: E1-E12, doi: 10.1002/mc.22120.

11. Slaby $\mathrm{O}$, Laga $\mathrm{R}$, Sedlacek $\mathrm{O}$. Therapeutic targeting of noncoding RNAs in cancer. Biochem J 2017; 474: 4219-4251, doi: 10.1042/BCJ20170079. 
12. Ding C, Yang Z, Lv Z, Du C, Xiao H, Peng C, et al. Long noncoding RNA PVT1 is associated with tumor progression and predicts recurrence in hepatocellular carcinoma patients. Oncol Lett 2015; 9: 955-963, doi: 10.3892/ol.2014.2730.

13. Nissan A, Stojadinovic A, Mitrani-Rosenbaum S, Halle D, Grinbaum R, Roistacher M, et al. Colon cancer associated transcript-1: a novel RNA expressed in malignant and premalignant human tissues. Int J Cancer 2012; 130: 15981606, doi: 10.1002/ijc.26170.

14. He X, Tan $X$, Wang $X$, Jin $H$, Liu L, Ma L, et al. C-Myc-activated long noncoding RNA CCAT1 promotes colon cancer cell proliferation and invasion. Tumour Biol 2014; 35: 12181-12188, doi: 10.1007/s13277-014-2526-4.

15. Deng L, Yang SB, Xu FF, Zhang JH. Long noncoding RNA CCAT1 promotes hepatocellular carcinoma progression by functioning as let-7 sponge. J Exp Clin Cancer Res 2015; 34: 18, doi: 10.1186/s13046-015-0136-7.

16. Shan T, Chen YG, Hong B, Zhou H, Xia JZ. [Expression and clinical significance of long non-coding RNA CCAT1 in gastric cancer]. Zhonghua Yi Xue Za Zhi 2017; 97: 14111414, doi: 10.3760/cma.j.issn.0376-2491.2017.18.012.

17. Wei J, Ma Z, Li Y, Zhao B, Wang D, Jin Y, et al. miR-143 inhibits cell proliferation by targeting autophagy-related $2 \mathrm{~B}$ in non-small cell lung cancer H1299 cells. Mol Med Rep 2015; 11: 571-576, doi: 10.3892/mmr.2014.2675.

18. Zhang C. MicroRNomics: a newly emerging approach for disease biology. Physiol Genomics 2008; 33: 139-14i, doi: 10.1152/physiolgenomics.00034.2008.

19. Couto MR, Goncalves P, Catarino TA, Martel F. The inflammatory status on butyrate and folate uptake $b$ (Caco-2) and non-tumoral (IEC-6) intestinal ep Cell J 2017; 19: 96-105, doi: 10.22074/cellj. clinical features of thyroid cancer in eastern Chin. Visc Surg 2010; 147: e53-e56, doi: 10 jj.jviscsurg..010. 02.007.

21. Cui B, Li B, Liu Q, Cui Y. IncRNA C ( T1 Pron es Glioma Tumorigenesis by Sponging miR-181b. schem 2017; doi: $10.1002 / j \mathrm{jcb} .26116$.

22. Akao $Y$, Nakagawa $Y$, Naoe Mir 143 and -145 in colon cancer. DNA Cell Biol 200 311-320, doi: 10.1089/ dna.2006.0550.

23. Chen $X$, Guo $X$, ang Xiand $Y$, Chen J, Yin $Y$, et al. Role of miR-143 $r$.ny in colorectal tumorigenesis. On jene 2.; 28: 1385-1392, doi: 10.1038/ onc.2008.4

24. Han X, Li.g Z $\lambda$, ’ng-Le GE, Qiang HU, Bin XU, Chen M, et al. ection of In NA CCAT1 on the proliferation,migratior and a ptosis of prostate cancer cell PC-3. Journal of So Univ ssity [in Chinese] 2017.

$25 \mathrm{~V}_{11} \mathrm{~B}$, $X$ ang $\mathrm{X}$, Tao J, Wu D, Wang Z, et al. miR-143 reaso ostate cancer cells proliferation and migration rease of KRAS. Mol Cel Biochem 2011; 350: 207, doi: 10.1007/ s11010-010-0700-6.

26. Ma CC, Zhang X, Zhu GN, Chao W, Gang Z, Wa HL tt al. Long non-coding RNA ATB promotes glioma : inn cy by negatively regulating miR-200a. Journal of Exp ental Clinical Cancer Research 2016; 35: 90.

27. Ma MZ, Chu BF, Zhang Y, Weng MZ, C YY, Gong W, et al. Long non-coding RNA CCAT1 promotes sladd cancer development via negative mod ...n of Cell Death Dis 2015; 6: e1583, : 10.1030"cdars.2014.541.

28. Zhao D, Pan C, Sun J, Gilber Drew Elger K, Azzam DJ, et al. VEGF drives ca r-ir. em cells through VEGFR-2/Stat3 signal 3 to regurate Myc and Sox2. Oncogene 2015; 3107- 9, doi: 10.1038/onc. 2014.257.

29. Zhang Z, Zhana $Y$, Sun $\lambda$ Ma X, Chen ZN. microRNA146a inhibits an metastásís by downregulating VEGF through du? athw cin hepatocellular carcinoma. Mol Cancer 2015; 14: 5, J.1roon 476-4598-14-5.

30. Zhang B, War Ji TF, Shi L, Yu JL. Overexpression of $\quad A N R I_{L}$, up-regulates VEGF expression and prom is a nesis of diabetes mellitus combined with cerebr. arction by activating NF-kappaB signaling pathway in at model. Oncotarget 2017; 8: 17347-17359, doi: 10.1 o32/oncotarget.14468.

31. gliuca A, Valvo C, Fabrizi E, di Martino S, Biffoni M, Runci D t al. Analysis of the combined action of miR-143 and R-145 on oncogenic pathways in colorectal cancer cells eveals a coordinate program of gene repression. Oncogene 2013; 32: 4806-4813, doi: 10.1038/onc.2012.495.

2. Wang L, Shi Z, Jiang C, Liu X, Chen Q, Qian X, et al. MiR143 acts as a tumor suppressor by targeting N-RAS and enhances temozolomide-induced apoptosis in glioma. Oncotarget 2014; 5: 5416-5427.

33. Manfredi GI, Dicitore A, Gaudenzi G, Caraglia M, Persani L, Vitale G. PI3K/Akt/mTOR signaling in medullary thyroid cancer: a promising molecular target for cancer therapy. Endocrine 2015; 48: 363-370, doi: 10.1007/s12020-0140380-1.

34. Shen CT, Qiu ZL, Song HJ, Wei WJ, Luo QY. miRNA-106a directly targeting RARB associates with the expression of $\mathrm{Na}(+) / /(-)$ symporter in thyroid cancer by regulating MAPK signaling pathway. J Exp Clin Cancer Res 2016; 35: 101, doi: 10.1186/s13046-016-0377-0.

35. Larson SD, Jackson LN, Riall TS, Uchida T, Thomas RP, Qiu S, et al. Increased incidence of well-differentiated thyroid cancer associated with Hashimoto thyroiditis and the role of the PI3k/Akt pathway. J Am Coll Surg 2007; 204: 764-773, doi: 10.1016/j.jamcollsurg.2006.12.037.

36. Xu J, Li Z, Su Q, Zhao J, Ma J. TRIM29 promotes progression of thyroid carcinoma via activating P13K/AKT signaling pathway. Oncol Rep 2017; 37: 1555-1564, doi: 10.3892/or.2017.5364. 